\title{
Sustained deep-tissue pain alters functional brain connectivity
}

\section{Citation}

Kim, Jieun, Marco L. Loggia, Robert R. Edwards, Ajay D. Wasan, Randy L. Gollub, and Vitaly Napadow. 2013. "Sustained Deep-Tissue Pain Alters Functional Brain Connectivity." Pain 154 (8) (August): 1343-1351. doi:10.1016/j.pain.2013.04.016.

\section{Published Version}

doi:10.1016/j.pain.2013.04.016

\section{Permanent link}

http://nrs.harvard.edu/urn-3:HUL.InstRepos:36303923

\section{Terms of Use}

This article was downloaded from Harvard University's DASH repository, and is made available under the terms and conditions applicable to Other Posted Material, as set forth at http:// nrs.harvard.edu/urn-3:HUL.InstRepos:dash.current.terms-of-use\#LAA

\section{Share Your Story}

The Harvard community has made this article openly available.

Please share how this access benefits you. Submit a story.

\section{Accessibility}




\title{
Sustained deep-tissue pain alters functional brain connectivity
}

\author{
Jieun Kim ${ }^{1,{ }^{*}}$, Marco L. Loggia ${ }^{1,2,3}$, Robert Edwards ${ }^{2,4}$, Ajay D. Wasan ${ }^{2,4}$, Randy L. \\ Gollub $^{1,3}$, and Vitaly Napadow ${ }^{1,2}$ \\ ${ }^{1} \mathrm{MGH} / \mathrm{MIT} / \mathrm{HMS}$ Athinoula A. Martinos Center for Biomedical Imaging, Charlestown, MA \\ ${ }^{2}$ Department of Anesthesiology, Perioperative and Pain Medicine, Brigham and Women's \\ Hospital, Harvard Medical School (HMS), Boston, MA \\ ${ }^{3}$ Department of Psychiatry, Massachusetts General Hospital, HMS, Boston, MA \\ ${ }^{4}$ Department of Psychiatry, Brigham and Women's Hospital, HMS, Boston, MA
}

\begin{abstract}
Recent functional brain connectivity studies have contributed to our understanding of the neurocircuitry supporting pain perception. However, evoked-pain connectivity studies have employed cutaneous and/or brief stimuli, which induce sensations that differ appreciably from the clinical pain experience. Sustained myofascial pain evoked by pressure cuff affords an excellent opportunity to evaluate functional connectivity change to more clinically-relevant sustained deeptissue pain. Connectivity in specific networks known to be modulated by evoked pain (sensorimotor, salience, dorsal attention, fronto-parietal control and default mode networks; SMN, SLN, DAN, FCN and DMN) was evaluated with functional-connectivity MRI, both at rest and during a sustained (6-minute) pain state in healthy adults. We found that pain was stable with no significant changes of subjects' pain ratings over the stimulation period. Sustained pain reduced connectivity between the SMN and the contralateral leg primary sensorimotor (S1/M1) representation. Such SMN-S1/M1 connectivity decreases were also accompanied by and correlated with increased SLN-S1/M1 connectivity, suggesting recruitment of activated S1/M1 from SMN to SLN. Sustained pain also increased DAN connectivity to pain processing regions such as mid-cingulate cortex, posterior insula and putamen. Moreover, greater connectivity during pain between contralateral S1/M1 and posterior insula, thalamus, putamen, and amygdala, was associated with lower cuff pressures needed to reach the targeted pain sensation. These results demonstrate that sustained pain disrupts resting S1/M1 connectivity by shifting it to a network known to process stimulus salience. Furthermore, increased connectivity between S1/M1 and both sensory and affective processing areas may be an important contribution to inter-individual differences in pain sensitivity.
\end{abstract}

\section{Keywords}

somatosensory; sensorimotor network; salience network; dorsal attention network; fronto-parietal control network; and functional connectivity

\footnotetext{
C 2013 International Association for the Study of Pain. Published by Elsevier B.V. All rights reserved.

"Correspondence should be addressed to: Jieun Kim, PhD, Massachusetts General Hospital, \#2301, 149 Thirteenth St., Charlestown, MA 02129, seesaw@nmr.mgh.harvard.edu, Phone: +1 617-513-7017; Fax: +1 617-726-7422.

Publisher's Disclaimer: This is a PDF file of an unedited manuscript that has been accepted for publication. As a service to our customers we are providing this early version of the manuscript. The manuscript will undergo copyediting, typesetting, and review of the resulting proof before it is published in its final citable form. Please note that during the production process errors may be discovered which could affect the content, and all legal disclaimers that apply to the journal pertain.
} 


\section{Introduction}

Neuroimaging analyses of functional brain connectivity have significantly impacted our understanding of brain function and the networks supporting perception of pain. Resting functional connectivity MRI (fcMRI) examines intrinsic connectivity, which may be important for maintenance of synaptic connectivity, follows known structural monosynaptic and polysynaptic pathways $[12 ; 41 ; 74]$, and likely reflects meaningful neurophysiological activity [56; 83] within known primary sensory, executive, and associative networks [30]. Both the magnitude and extent of connectivity within these networks appear to be modulated by perceptual states, including clinical pain [50; 51].

While pain studies using healthy volunteers typically evaluate responses to experimentallyinduced pain, they might also have important implications for understanding the pathophysiology underlying chronic pain in patients. However, previous analyses have not yet evaluated how functional connectivity is altered during sustained experimentallyinduced pain in otherwise healthy subjects. This is an important step in understanding how the experience of persistent pain alters brain function, since differences between chronic pain and healthy control groups may be shaped by dozens of potentially confounding factors such as medical comorbidities, medication history, physical inactivity, emotional processes, etc.

In healthy adults, Peltz et al. found that insular connectivity was altered in scans where experimental pain stimuli are presented in blocks, though this study was unable to evaluate connectivity changes during continuous noxious stimulation [55]. Interestingly, insular connectivity immediately preceding liminal (pain-threshold) stimuli determines whether such stimuli are perceived as painful [57]. Multiple studies have suggested that resting brain connectivity is altered in chronic pain patients $[4 ; 14-16 ; 45 ; 51 ; 72]$, and connectivity between the brain's default mode network $[11 ; 62 ; 67]$ and insula may specifically relate to clinical pain intensity $[43 ; 50 ; 51]$. Functional connectivity has not yet been evaluated during sustained experimental pain most likely because continuous administration of many experimentally applied pain stimuli (e.g. heat) risks permanent tissue damage. Thus, it is unknown if the altered resting connectivity noted in chronic pain patients differs from sustained pain state connectivity in healthy adults.

Additionally, it is also unknown how functional connectivity during sustained pain relates to pain sensitivity, which is known to vary widely between individuals [54]. Neuroimaging markers, such as pain-evoked activations, have been noted to track with individual difference in subjects' sensitivity to pain stimuli [19]. However, functional brain connectivity during sustained pain has never been explored for this purpose, and might inform our understanding of the neurophysiology underlying inter-individual differences in pain sensitivity.

In this study, we hypothesized that sustained pain alters functional connectivity for brain networks known to respond to experimental pain stimuli. Functional brain connectivity was evaluated at rest and during a sustained pain state evoked by cuff pressure algometry, a technique that allows for a continuous, deep-receptor pain stimulus. Compared to most cutaneous pain techniques, deep tonic pain may better mimic clinical pain [23;64] and can be sustained for minutes without significant risk of tissue damage [59]. We also hypothesized that inter-subject differences in cuff pain sensitivity could be predicted by variability in functional brain connectivity present in the sustained pain state. 


\section{Methods}

This study evaluated functional brain connectivity during sustained cuff pain, and compared this response to resting brain connectivity, evaluated in the same subjects.

\section{Participants}

Eighteen (18), right handed, healthy volunteers were enrolled in this study. All participants gave written informed consent in accordance with the Human Research Committee of the Massachusetts General Hospital. Of these subjects, one was excluded after the training session due to unreliable pain ratings and another was disqualified following the MRI session due to excessive motion artifacts. Data from 16 subjects $(11$ male, age $=28 \pm 9.7$ years; mean $\pm \mathrm{SD}$ ) were analyzed. Exclusion criteria for our healthy adults included: age below 18 years old, chronic or acute pain, neurological disorders including peripheral neuropathy, history of significant head injury, serious cardiovascular disease, current use of medications and/or recreational drugs, and standard contraindications for MRI.

\section{Pain Stimulation and Experimental protocol}

Participants received a painful pressure stimulus on their left lower leg (over the gastrocnemius muscle) continuously for 6 minutes. Pressure stimuli were delivered with a velcro-adjusted pressure cuff (SC12D, Hokanson Inc, Belleveue, WA, USA), connected to a rapid cuff inflator (Hokanson E20 AG101), which inflated the cuff to a constant, individually-tailored pressure level. This type of cuff pressure algometry is a recentlycharacterized method that is now included in many quantitative sensory testing evaluations [34]. One advantage to the application of cuff algometry is that unlike more superficial methods of evaluating mechanical sensitivity, cuff pain responses are only marginally affected by sensitization or desensitization of the skin, indicating that this procedure primarily assesses sensitivity in muscle and other deep tissues [58; 59]. Moreover, cuff pain at high intensities can be safely applied for extended periods of time (as much as 20 minutes, see [59]) without producing tissue damage.

Prior to imaging, subjects participated in a training session to familiarize themselves with the stimuli and rating procedures. The pressure level that produced a pain intensity rating of $\sim 50 / 100$ was determined for each subject during the training session, and recalibrated just before the imaging session.

The fMRI session included a 6-minute resting state scan run (REST), which was followed by a 6-minute run with continuous pressure pain stimulation (PAIN). The cuff inflator was initiated at least 10 seconds before fMRI data were collected in order to remove any brain response due to a generalized startle reflex. The cuff was fully inflated within $2 \sim 3$ seconds after initiation by button press. The order was not counter-balanced to assure that any lingering pain sensation experienced during the PAIN run would not interfere with resting brain connectivity during REST. For both REST and PAIN, subjects were instructed to relax and lie still with their eyes open.

After the PAIN run, subjects were asked to rate the intensity and unpleasantness of pain from the cuff. Subjects provided ratings for each of the 2-minute blocks at the beginning, middle, and end of the 6-minute procedure in order to retrospectively evaluate potential sensitization or adaptation to the lengthy pain stimulus. A 0-100 numeric pain rating scale was used, where 0 was labeled "no pain" for the pain intensity and "neutral" for the pain unpleasantness, and 100 was labeled "the most intense pain tolerable" for the pain intensity and "extremely unpleasant" for the pain unpleasantness. Subjects were trained to distinguish intensity and unpleasantness of pain using a brief text similar to that employed by Price and colleagues [60], a method shown to allow dissociation between sensory and affective 
components of the pain experience $[44 ; 77 ; 78]$. A repeated measures analysis of variance was used to compare ratings from the three 2-minute periods of the 6-minute pain stimulus (SPSS, PASW Statistics 18.0, IBM, Armonk, NY). We also performed post-hoc testing using Dunnett's test in order to compare the first 2-minute period with the middle and last 2minute periods in order to evaluate sensitization or adaptation to pain stimulation. All results were reported significant at $\mathrm{p}<0.05$.

The REST and PAIN runs were separated by three functional runs during which a series of calibrated cuff stimuli were delivered. The brain responses to these stimuli allowed us to identify regions responding linear and nonlinearly to pain (see [42] for details), and these results were also used to define seeds for functional connectivity analyses on data from the 6 minute REST and PAIN scans.

\section{MRI and Physiological Data collection}

Functional MRI (fMRI) data were acquired using a 3T Siemens TIM Trio MRI system (Siemens Medical, Erlangen, Germany) equipped for echo planar imaging with a 32-channel head coil. A whole brain T2*-weighted gradient echo BOLD pulse sequence (TR/ $\mathrm{TE}=2000 / 30 \mathrm{~ms}$, f.a. $=90^{\circ}, 32 \mathrm{AC}-\mathrm{PC}$ aligned axial slices, voxel size $=3.1 \times 3.1 \times 4 \mathrm{~mm}$ ) was used. Anatomical data were also collected using a multi-echo MPRAGE pulse sequence $\left(\mathrm{TR} / \mathrm{TE} 1 / \mathrm{TE} 2 / \mathrm{TE} 3 / \mathrm{TE} 4=2530 / 1.64 / 3.5 / 5.36 / 7.22 \mathrm{~ms}, \mathrm{f} . \mathrm{a} .=7^{\circ}\right.$, voxel size $\left.=1 \times 1 \times 1 \mathrm{~mm}^{3}\right)$.

Physiological data were collected simultaneously to the fMRI data, as cardio-respiratory fluctuation is known to influence fMRI intrinsic connectivity estimation within several brain networks $[7 ; 17 ; 18]$. The Electrocardiogram (ECG) data were collected with an MRIcompatible Patient Monitoring system (Model 3150, Invivo Research Inc., Orlando, FL) through MRI-compatible electrodes (VerMed, Bellows Falls, VT) on the chest. Respiration data were collected using a custom built MR-compatible belt placed around the subject's ribcage [6]. All physiological signals were collected at $400 \mathrm{~Hz}$ using Chart Data Acquisition Software on a laptop using the Powerlab System (ADInstruments Inc., Colorado Springs, $\mathrm{CO})$.

\section{MRI Data Pre-processing}

Functional MRI data were pre-processed using the validated FSL (FMRIB's Software Library, http://www.fmrib.ox.ac.uk/fsl/), AFNI (afni.nimh.nih.gov/afni, and FreeSurfer (http://surfer.nmr.mgh.harvard.edu/) software packages. Data were corrected for cardiorespiratory artifacts using RETROICOR [33]. Cardiac beat annotation and respiratory volume calculation were performed using custom scripts in Matlab (The MathWorks, Natick, MA). The ECG traces and respiration data were resampled at $40 \mathrm{~Hz}$ to be used in RETROICOR, and the cardiac and respiratory response functions were calculated to use as nuisance regressor $[17 ; 33]$.

Head motion correction used FSL-MCFLIRT [38]. As recent studies suggest that head motion during scanning may influence functional connectivity [75], computation of head motion metrics was performed using the same methods reported previously by Van Dijk et al. [75]. The mean translation was computed as the root-mean-square (RMS) of the estimated motion translation parameters in $\mathrm{x}, \mathrm{y}$ and $\mathrm{z}$ directions, while mean rotation was computed using Euler angle from the estimated motion angular components. The difference in mean translation (REST: $0.02 \pm 0.01 \mathrm{~mm}$, mean \pm SD; PAIN: $0.03 \pm 0.02$ ) and mean rotation (REST: $0.33 \pm 0.11$ radians x 1000 , mean \pm SD; PAIN: $0.37 \pm 0.14$ ) between REST and PAIN was not statistically significant (mean translation: $p=0.39$, rotation: $p=0.11$ ). Brain extraction was performed using FSL-BET [68]. Cortical surface reconstruction was completed to perform improved structural-functional co-registration using FreeSurfer's 
bbregister tool [35]. Functional data were then registered to standard Montreal Neurological Institute (MNI) space using FMRIB's nonlinear co-registration tool (FNIRT). Functional data were smoothed using a Gaussian kernel of FWHM 6mm and high-pass temporal filtering $(\mathrm{f}=0.008 \mathrm{~Hz})$ was performed.

\section{Functional Connectivity: Independent Component Analysis (ICA)}

Functional connectivity MRI analysis was performed using the validated dual-regression ICA approach [29; 84]. This approach uses the Multivariate Exploratory Linear Optimized Decomposition into Independent Components (FSL-MELODIC) tool, and our application was similar to our past published studies [50; 51].

This approach consists of three stages. First, a probabilistic Independent Component Analysis (pICA, MELODIC, FSL) was applied on concatenated, preprocessed functional data from both REST and PAIN runs from all subjects. We limited the number of independent components (ICs) to 25 , as in previous publications using the dual regression approach $[29 ; 50 ; 51]$. From the pool of $25 \mathrm{ICs}$, we selected functionally relevant ICs using spatial correlation with previously defined templates provided by Beckmann et al. [5]. In the second stage, these independent spatial maps were used in a general linear model (spatial regression model) as a spatial regressor for each individual subject. The temporal dynamics were calculated for each IC of interest at the subject level.

In the third stage of dual regression, this fMRI time series from each subject was variance normalized and used in a subject-level general linear model (temporal regression model) to reconstruct spatial maps for each subject. In order to limit any residual shared variance with non-neuronal response, nuisance regressors were included in this model: (1) fMRI time series from white matter and ventricular regions, (2) motion correction time series for the six translation/rotation parameters reflecting rigid body head motion correction, and (3) cardiorespiratory artifacts defined by convolving the heart rate and respiratory variation time series with appropriate cardiac and respiratory transfer functions, as defined by Chang et al. [17] and Birn et al. [8], respectively. No global signal regression was used in this analysis. Reconstructed independent spatial maps were then input into our higher-level analyses for within- and between-subject group analyses.

Our analyses were focused on several pain-related RSNs: the salience network (SLN), sensorimotor network (SMN), dorsal attention network (DAN), fronto-parietal control (FCN), and the default mode network (DMN). The SLN is known to be encompassed by bilateral anterior insula and dorsal anterior cingulate areas [66] regions commonly activated by experimental pain stimuli [3]. The SMN includes pre- and post-central gyri and supplementary motor area [9], regions also commonly activated by somatosensory stimuli, including pain. The DAN includes regions in the frontal eye fields (FEF), superior parietal lobule, intraparietal sulcus, and middle temporal area $(\mathrm{MT}+)$ [14; 31; 79]. The FCN is composed of rostrolateral prefrontal cortex (rsPFC), middle frontal gyrus, lateral parietal and anterior insula/frontal operculum $[14 ; 69 ; 70 ; 79]$. The DMN is known to include medial frontal cortex (MPFC), posterior cingulate cortex (PCC) and precuneus, inferior parietal lobule (IPL), lateral temporal cortex and hippocampal formation $[11 ; 62]$. This network is typically deactivated by evoked pain and other external stimuli, and its connectivity is altered in chronic pain conditions in a clinical pain intensity-dependent manner [50; 51]. Individuals' reconstructed resting state networks were then passed up to group level analyses, performed using FLAME (FMRIB's Local Analysis of Mixed Effects). All maps were thresholded using cluster correction for multiple comparisons with a cluster-forming threshold of $Z>2.3$, and cluster-size significance of $p<0.05$. 
As we found that sustained pain decreased SMN connectivity to S1/M1 and increased SLN connectivity to the same region (see Results), an inter-subject correlation analysis explored whether subjects with decreased SMN connectivity were the same as those with increased SLN connectivity. Peak response from the SMN and SLN difference map was extracted and entered into a one-tailed Pearson's correlation test, reported significant at $\mathrm{p}<0.05$.

\section{Functional Connectivity: Seed based correlation analysis}

As our dual regression ICA approach identified altered SMN and SLN connectivity to contralateral (right) primary sensory/motor cortex (S1/M1), at the level of the paracentral lobule (i.e., sensorimotor representation of the leg), we chose this S1/M1 area as a seed to further explore how sustained pain alters connectivity between this region and the rest of the brain. We used a functional localizer taken from different scans - i.e. the contralateral somatotopic S1/M1 cluster demonstrating linearly increasing fMRI response to linearly increasing cuff pain stimuli, as reported in our previous study [42]. The S1/M1 correlation maps were produced by extracting the fMRI time series from the preprocessed fMRI data with a $4 \mathrm{~mm}$ radius sphere centered at MNI coordinates: $x=10, y=36, z=68 \mathrm{~mm}$. The extracted fMRI time series, variance normalized, was used as a regressor in a general linear model for the REST and PAIN data. The same nuisance regressors adopted in the dual regression analyses (see above) were included in this model as well. Group brain maps were thresholded $(Z>2.3)$ using cluster correction with cluster significance of $p<0.05$.

\section{Correlation between S1/M1 Functional Connectivity and Stimulus Intensity}

In order to investigate the link between primary sensorimotor functional connectivity and individual differences in cuff pressure used to reach the targeted pain sensation, we performed a linear regression with S1/M1 functional connectivity data from the PAIN run as dependent variable, and cuff-pressure levels (in $\mathrm{mmHg}$ ) individually determined to produce the 50/100 pain intensity as the independent variable. Results were reported significant at cluster corrected $\mathrm{p}<0.05$.

\section{Results}

All subjects who completed the fMRI session tolerated the cuff stimulus for the full duration of 6 minutes. All subjects reported that the cuff pain had abated within 30 seconds following cuff deflation.

\section{Psychophysical Response to Sustained Pain}

A repeated measure analysis of variance on the ratings from three 2-minute periods revealed no statistically significant changes over time in either cuff pain intensity or unpleasantness $(\mathrm{F}(2,30)=1.50, \mathrm{p}=0.24$ for pain intensity, $\mathrm{F}(2,30)=1.21, \mathrm{p}=0.31$ for pain unpleasantness $)$. Dunnett's test was performed using the first 2-minute period as reference timepoint to evaluate sensitization or adaptation to sustained pain stimulation. There was no statistically significant changes between the first 2-minute and second 2-minute ( $\mathrm{p}=0.36$ for pain intensity and 0.75 for pain unpleasantness), nor between the first 2-minute and last 2-minute ( $\mathrm{p}=0.75$ for pain intensity and 0.48 for pain unpleasantness) periods (Figure 1 ).

\section{Functional Brain Connectivity Response to Sustained Pain}

The ICA group maps for SMN, SLN, DAN, FCN and DMN were successfully identified and were very similar to networks previously described [5;66] (Supplementary Figure 1). Connectivity maps across experimental conditions revealed that functional connectivity was altered during PAIN compared to REST. While connectivity between SMN and a cluster within the primary somatosensory/motor cortex (S1/M1) was reduced during PAIN, the 
connectivity between the SLN and a near identical S1/M1 cluster was increased (Figure 2,

Table 1). This S1/M1 cluster was located at the level of the right paracentral lobule, i.e., the contralateral somatotopic location of the left lower leg, where the cuff was placed. A significant correlation $(\mathrm{r}=-0.46, \mathrm{p}<0.05)$ was found between decreased SMN-S1/M1 connectivity and increased SLN-S1/M1 connectivity (Figure 3).

Other networks were also significantly modulated by sustained pain. During PAIN, the DAN showed greater correlation (or less anti-correlation, see Table 1) to preSMA, MCC, left posterior insula, left putamen, as well as midbrain (nuclei raphe dorsalis/nuclei cuneiform, NRD/NCF), pontine, reticular formation (consistent with locus ceruleus), and cerebellar (bilateral lobule VI 1) nuclei. Greater anti-correlation between right FCN and both S1/M1 and precuneus was also found during PAIN (Figure 4, Table 1). A whole brain analysis contrasting DMN connectivity between PAIN and REST did not yield any significant clusters.

The changes in functional connectivity during sustained pain, as resolved with the networkbased ICA analysis were also broadly supported by our contralateral S1/M1 seed connectivity analysis (see Methods). During PAIN, contralateral leg-region S1/M1 connectivity to bilateral S1/M1 areas outside of this leg region was significantly decreased (i.e. broadly consistent with decreased SMN connectivity to contralateral leg-region S1/M1) (Figure 5, Table 1). However, contralateral leg-region S1/M1 connectivity to right anterior insula was significantly increased (i.e. broadly consistent with increased S1/M1 connectivity to SLN, while specifically implicating the right anterior insula node of this network) (Figure 5 , Table 1).

\section{Stimulus Intensity was Associated with S1/M1 Connectivity During PAIN}

Cuff pressure was individually tailored to evoke a 50/100 pain intensity in all subjects. Cuff pressure ranged from 110 to $410 \mathrm{mmHg}(253.81 \pm 75.76$, mean $\pm \mathrm{SD})$, which indicates that subjects exhibited a wide range of cuff pressure. In order to determine whether somatotopic (leg region) S1/M1 functional connectivity during sustained pain could, in part, explain such heterogeneity, linear regression analysis was performed using the cuff pressure as explanatory variable. We found that higher cuff pressure eliciting 50/100 pain was associated with less somatotopic S1/M1 connectivity to a significant cluster including left putamen, thalamus, amygdala and posterior insula (Figure 6, Table 2). Thus, less sensitive participants (i.e., those experiencing higher cuff pressures) demonstrated less contralateral S1/M1 connectivity to these brain areas.

\section{Discussion}

Our study found that sustained pain led to a distinct shift in functional brain connectivity. The somatotopic representation of the noxiously stimulated leg in the primary sensorimotor cortex became less connected with other primary sensorimotor regions, and more connected to brain regions comprising the salience network (insula, mid-cingulate). Moreover, increased connectivity between somatotopically defined primary sensorimotor cortex and other sensory as well as affective brain areas may be an important contribution to interindividual differences in pain sensitivity.

When the brain is at rest, different S1/M1 cortical representation regions are in direct communication, leading to robust inter-connectivity within the so-called sensorimotor network [5]. During somatosensory perception, a somatotopic representation in contralateral $\mathrm{S} 1 / \mathrm{M} 1$ is activated. Our results demonstrated that when this S1/M1 somatotopic representation was processing peripheral noxious afference, its resting connectivity with neighboring S1/M1 sub-regions (i.e., with the sensorimotor network) was disrupted. In 
addition, connectivity between this contralateral somatotopic S1/M1 subregion and the salience network, particularly the insula, was augmented. Thus, while canonical connectivity networks, such as the SMN and SLN, remain grossly intact during sustain pain processing, the extent of these networks is altered to exclude or include brain areas activated by the stimulus. The anterior insula and mid-cingulate cortices, as salience network areas [24; 49; 66], have been postulated to assign homeostatic relevance for both internal and external sensory inputs to the brain [21], and are key regions of affective and attentional processing of pain stimuli $[63 ; 81]$. Moreover, linked activity within the anterior insula and midcingulate cortex may play a role in integrating cognitive, affective, and interoceptive processing in order to produce behavioral and autonomic motor response [47]. Hence, the increased connectivity between somatotopic $\mathrm{S} 1$ and salience network regions likely reflects a multi-dimensional attribution of relevance to the ongoing painful stimulus. Similarly, increased DAN connectivity to known pain processing regions such as the MCC, midbrain (NCF), posterior insula, and putamen during PAIN likely also relate to the shifting of, in this case, more basic attentional resources toward processing of the ongoing pain stimulus.

Other non-painful, unilateral sensorimotor tasks have been shown to produce similar disruptions in functional connectivity. For instance, reduction in left-right S1/M1 synchrony was found during unilateral continuous performance of a finger tapping task [2;48;53]. Contralateral somatotopic M1 connectivity to mid-cingulate and insula was not reported by these studies, and this connectivity may prove to be more pronounced during tasks with arguably greater salience to the organism, such as evoked pain. However, reduced interhemispheric connectivity in response to a unilateral motor task is similar to our findings for unilateral pain, and suggests that such inter-hemispheric de-coupling is a consistent phenomenon across multiple unilateral tasks, which might underlie spatial localization [37] and/or suppression of irrelevant sensory information, thereby enhancing processing of signals expected to carry greater behavioral significance $[25 ; 36 ; 39 ; 40 ; 80]$. Future studies should also evaluate functional connectivity during a broader range of noxious and innocuous somatosensory stimuli as, for instance, SLN recruitment of S1/M1 may be modulated in an intensity-dependent manner.

Individual differences in pain sensitivity greatly influences diagnosis and treatment of chronic pain patients [19]. There are also important implications for pain chronification in healthy adults, although this is more controversial [27]. Neuroimaging studies have found that more sensitive individuals exhibited more frequent and more robust pain-induced activation in brain regions involved in affect as well as attention and decision-making [20]. However, functional connectivity during sustained pain has never been evaluated as a potential determinant of pain sensitivity.

We noted that the cuff pressure necessary to evoke the same moderate pain intensity varied widely (from 110 to $410 \mathrm{mmHg}$ ) across our healthy volunteer group. This wide variability would not allow for a stimulus-matched experimental design to explore inter-individual differences in pain sensitivity, as no single pressure would (1) be painful and (2) tolerable for all subjects. Hence we inferred pain sensitivity from our percept-matched analysis by using cuff pressure as independent variable. We found that individuals highly sensitive to cuff pressure stimulation (i.e. requiring lower cuff pressures) demonstrated greater contralateral somatotopic S1/M1 functional connectivity with brain regions known to process both the sensory and affective dimensions of pain (thalamus, posterior insula, putamen, and amygdala). The thalamus is commonly found to respond to evoked pain [3; 26]. In our study the specific localization of the thalamic cluster was likely the ventral posterolateral nucleus (VPL), which relays sensory-discriminative information to the primary somatosensory cortex [14], and shows reduced connectivity to S1 in diabetic neuropathic pain patients [15]. Similarly, the posterior insula responds to nociceptive 
afference and the sensory-discriminative dimension of pain [3; 22; 46], a contention supported by stimulus-response mapping in both neuroimaging [10] and intra-cranial evoked potential [32] studies. The putamen is also commonly activated in evoked pain studies [3] and may be involved in sensory aspects of pain processing, as suggested by a recent human brain lesion study [71]. On the other hand, the amygdala is a key region for fear and emotion processing [82], which likely supports the affective dimension of pain processing. Greater connectivity between this region and brain regions known to support the sensorydiscriminative dimension of pain (i.e. S1), might form the neurophysiological substrate underlying the greater pain and pain-related negative emotions [28] reported by highly sensitive individuals. In sum, while there exist multiple known factors that contribute to inter-individual variability in pain sensitivity (e.g. gender, age, genetics, and psychosocial functioning), inter-individual variability in functional brain connectivity may also contribute to this heterogeneity in subjective pain report. Future studies may benefit from the application of fcMRI to help categorize and diagnose pain patients, as well as identifying individuals most likely to benefit from particular treatments.

In most pain neuroimaging studies, noxious stimulation has been delivered using thermal, laser, and electrical shock stimuli [3]. In general, due to the risk of tissue damage, such studies have been unable to apply tonic painful stimulation for a long enough period to evaluate pain-related changes in functional connectivity. Moreover, these methods stimulate, primarily or exclusively, cutaneous and superficial afferent fibers. In this study we utilized cuff pressure algometry. This technique stimulates muscle and other deep nociceptors [58; 59] and can be safely applied for extended periods of time without damaging the underlying tissue. Thus, we were able, for the first time, to report on brain functional connectivity changes induced by a sustained, deep tissue pain stimulus, which is known to better mimic clinical pain [23; 64].

Several limitations to this study should be noted. For instance, gender is known to influence individual variability in pain sensitivity [61]. However, our study did not include enough subjects to separately evaluate males and females in regard to functional connectivity predictors for pain sensitivity. Additionally, we cannot state that all of our results are specific to evoked deep-tissue pain, as we did not evaluate how, for example, a non-painful somatosensory stimulation modulates functional brain connectivity. However, previous studies applying fcMRI during non-painful sensorimotor tasks $[1 ; 52]$ did not report altered connectivity outside of primary and secondary sensorimotor regions. Finally, after the 6minute PAIN scan, subjects were asked to rate pain over 3 different temporal windows - a procedure that may have required greater cognitive effort than rating pain for a single shorter-duration stimulus provocation. We cannot rule out the possibility that increased working memory or cognitive load from this pain rating procedure influenced our results. However, our subjects were well trained in discriminating different pain intensities and several studies using a variety of methodologies have noted that individuals are generally quite proficient at remembering pain intensity levels over spans of time ranging from minutes $[13 ; 76]$ to days $[65 ; 73]$.

In summary, the main findings of our study demonstrate that 1) sustained pain alters functional brain connectivity, shifting S1/M1 connectivity from the SMN to SLN brain regions and 2) inter-individual differences in pain sensitivity were associated with variability in sensorimotor functional connectivity evaluated during the sustained pain stimulus.

\section{Supplementary Material}

Refer to Web version on PubMed Central for supplementary material. 


\section{Acknowledgments}

We would like to thank NIH for funding support (VN: R01-AT004714, P01-AT002048; AW: 1K23DA020681-01A1), the NCRR (P41RR14075; CRC 1 UL1 RR025758, Harvard Clinical and Translational Science Center). Dr. Edwards received support for this study from the American College of Rheumatology and the Arthritis Foundation.

The content is solely the responsibility of the authors and does not necessarily represent the official views of our sponsors.

\section{References}

1. Amann M, Hirsch JG, Gass A. A serial functional connectivity MRI study in healthy individuals assessing the variability of connectivity measures: reduced interhemispheric connectivity in the motor network during continuous performance. Magn Reson Imaging. 2009

2. Amann M, Hirsch JG, Gass A. A serial functional connectivity MRI study in healthy individuals assessing the variability of connectivity measures: reduced interhemispheric connectivity in the motor network during continuous performance. Magn Reson Imaging. 2009; 27(10):1347-1359. [PubMed: 19559557]

3. Apkarian AV, Bushnell MC, Treede RD, Zubieta JK. Human brain mechanisms of pain perception and regulation in health and disease. Eur J Pain. 2005; 9(4):463-484. [PubMed: 15979027]

4. Baliki MN, Baria AT, Apkarian AV. The cortical rhythms of chronic back pain. J Neurosci. 2011; 31(39):13981-13990. [PubMed: 21957259]

5. Beckmann CF, DeLuca M, Devlin JT, Smith SM. Investigations into resting-state connectivity using independent component analysis. Philos Trans R Soc Lond B Biol Sci. 2005; 360(1457):10011013. [PubMed: 16087444]

6. Binks AP, Banzett RB, Duvivier C. An inexpensive, MRI compatible device to measure tidal volume from chest-wall circumference. Physiol Meas. 2007; 28(2):149-159. [PubMed: 17237587]

7. Birn RM, Murphy K, Bandettini PA. The effect of respiration variations on independent component analysis results of resting state functional connectivity. Hum Brain Mapp. 2008; 29(7):740-750. [PubMed: 18438886]

8. Birn RM, Smith MA, Jones TB, Bandettini PA. The respiration response function: the temporal dynamics of fMRI signal fluctuations related to changes in respiration. Neuroimage. 2008; 40(2): 644-654. [PubMed: 18234517]

9. Biswal B, Yetkin FZ, Haughton VM, Hyde JS. Functional connectivity in the motor cortex of resting human brain using echo-planar MRI. Magn Reson Med. 1995; 34(4):537-541. [PubMed: 8524021]

10. Bornhovd K, Quante M, Glauche V, Bromm B, Weiller C, Buchel C. Painful stimuli evoke different stimulus-response functions in the amygdala, prefrontal, insula and somatosensory cortex: a single-trial fMRI study. Brain. 2002; 125(Pt 6):1326-1336. [PubMed: 12023321]

11. Buckner RL, Andrews-Hanna JR, Schacter DL. The brain's default network: anatomy, function, and relevance to disease. Ann N Y Acad Sci. 2008; 1124:1-38. [PubMed: 18400922]

12. Buckner RL, Krienen FM, Castellanos A, Diaz JC, Yeo BT. The organization of the human cerebellum estimated by intrinsic functional connectivity. Journal of neurophysiology. 2011; 106(5):2322-2345. [PubMed: 21795627]

13. Campbell CM, Kronfli T, Buenaver LF, Smith MT, Berna C, Haythornthwaite JA, Edwards RR. Situational versus dispositional measurement of catastrophizing: associations with pain responses in multiple samples. The journal of pain: official journal of the American Pain Society. 2010; 11(5):443-453. e442. [PubMed: 20439057]

14. Cauda F, D'Agata F, Sacco K, Duca S, Cocito D, Paolasso I, Isoardo G, Geminiani G. Altered resting state attentional networks in diabetic neuropathic pain. Journal of neurology, neurosurgery, and psychiatry. 2010; 81(7):806-811.

15. Cauda F, Sacco K, D’Agata F, Duca S, Cocito D, Geminiani G, Migliorati F, Isoardo G. Lowfrequency BOLD fluctuations demonstrate altered thalamocortical connectivity in diabetic neuropathic pain. BMC neuroscience. 2009; 10:138. [PubMed: 19941658] 
16. Cauda F, Sacco K, Duca S, Cocito D, D’Agata F, Geminiani GC, Canavero S. Altered resting state in diabetic neuropathic pain. PLoS ONE. 2009; 4(2):e4542. [PubMed: 19229326]

17. Chang C, Cunningham JP, Glover GH. Influence of heart rate on the BOLD signal: the cardiac response function. Neuroimage. 2009; 44(3):857-869. [PubMed: 18951982]

18. Chang C, Glover GH. Relationship between respiration, end-tidal CO2, and BOLD signals in resting-state fMRI. NeuroImage. 2009; 47(4):1381-1393. [PubMed: 19393322]

19. Coghill RC. Individual differences in the subjective experience of pain: new insights into mechanisms and models. Headache. 2010; 50(9):1531-1535. [PubMed: 20958300]

20. Coghill RC, McHaffie JG, Yen YF. Neural correlates of interindividual differences in the subjective experience of pain. Proc Natl Acad Sci U S A. 2003; 100(14):8538-8542. [PubMed: 12824463]

21. Craig AD. How do you feel--now? The anterior insula and human awareness. Nat Rev Neurosci. 2009; 10(1):59-70. [PubMed: 19096369]

22. Craig AD, Chen K, Bandy D, Reiman EM. Thermosensory activation of insular cortex. Nat Neurosci. 2000; 3(2):184-190. [PubMed: 10649575]

23. Curatolo M, Petersen-Felix S, Arendt-Nielsen L. Assessment of regional analgesia in clinical practice and research. Br Med Bull. 2004; 71:61-76. [PubMed: 15684246]

24. Downar J, Crawley AP, Mikulis DJ, Davis KD. A cortical network sensitive to stimulus salience in a neutral behavioral context across multiple sensory modalities. J Neurophysiol. 2002; 87(1):615620. [PubMed: 11784775]

25. Drevets WC, Burton H, Videen TO, Snyder AZ, Simpson JR Jr, Raichle ME. Blood flow changes in human somatosensory cortex during anticipated stimulation. Nature. 1995; 373(6511):249-252. [PubMed: 7816140]

26. Duerden EG, Albanese MC. Localization of pain-related brain activation: A meta-analysis of neuroimaging data. Hum Brain Mapp. 2011

27. Edwards RR. Individual differences in endogenous pain modulation as a risk factor for chronic pain. Neurology. 2005; 65(3):437-443. [PubMed: 16087910]

28. Edwards RR, Cahalan C, Mensing G, Smith M, Haythornthwaite JA. Pain, catastrophizing, and depression in the rheumatic diseases. Nature reviews Rheumatology. 2011; 7(4):216-224.

29. Filippini N, MacIntosh BJ, Hough MG, Goodwin GM, Frisoni GB, Smith SM, Matthews PM, Beckmann CF, Mackay CE. Distinct patterns of brain activity in young carriers of the APOEepsilon4 allele. Proc Natl Acad Sci U S A. 2009; 106(17):7209-7214. [PubMed: 19357304]

30. Fox MD, Raichle ME. Spontaneous fluctuations in brain activity observed with functional magnetic resonance imaging. Nat Rev Neurosci. 2007; 8(9):700-711. [PubMed: 17704812]

31. Fox MD, Snyder AZ, Vincent JL, Corbetta M, Van Essen DC, Raichle ME. The human brain is intrinsically organized into dynamic, anticorrelated functional networks. Proc Natl Acad Sci U S A. 2005; 102(27):9673-9678. [PubMed: 15976020]

32. Frot M, Magnin M, Mauguiere F, Garcia-Larrea L. Human SII and posterior insula differently encode thermal laser stimuli. Cereb Cortex. 2007; 17(3):610-620. [PubMed: 16614165]

33. Glover GH, Li TQ, Ress D. Image-based method for retrospective correction of physiological motion effects in fMRI: RETROICOR. Magn Reson Med. 2000; 44(1):162-167. [PubMed: 10893535]

34. Graven-Nielsen T, Arendt-Nielsen L. Assessment of mechanisms in localized and widespread musculoskeletal pain. Nat Rev Rheumatol. 2010; 6(10):599-606. [PubMed: 20664523]

35. Greve DN, Fischl B. Accurate and robust brain image alignment using boundary-based registration. Neuroimage. 2009; 48(1):63-72. [PubMed: 19573611]

36. Haxby JV, Horwitz B, Ungerleider LG, Maisog JM, Pietrini P, Grady CL. The functional organization of human extrastriate cortex: a PET-rCBF study of selective attention to faces and locations. J Neurosci. 1994; 14(11 Pt 1):6336-6353. [PubMed: 7965040]

37. Hlushchuk Y, Hari R. Transient suppression of ipsilateral primary somatosensory cortex during tactile finger stimulation. J Neurosci. 2006; 26(21):5819-5824. [PubMed: 16723540] 
38. Jenkinson M, Bannister P, Brady M, Smith S. Improved optimization for the robust and accurate linear registration and motion correction of brain images. Neuroimage. 2002; 17(2):825-841. [PubMed: 12377157]

39. Kawashima R, O'Sullivan BT, Roland PE. Positron-emission tomography studies of crossmodality inhibition in selective attentional tasks: closing the "mind's eye". Proc Natl Acad Sci U S A. 1995; 92(13):5969-5972. [PubMed: 7597062]

40. Klingner CM, Hasler C, Brodoehl S, Witte OW. Dependence of the negative BOLD response on somatosensory stimulus intensity. Neuroimage. 2010; 53(1):189-195. [PubMed: 20538064]

41. Krienen FM, Buckner RL. Segregated fronto-cerebellar circuits revealed by intrinsic functional connectivity. Cereb Cortex. 2009; 19(10):2485-2497. [PubMed: 19592571]

42. Loggia ML, Edwards RR, Kim J, Vangel MG, Wasan AD, Gollub RL, Harris RE, Park K, Napadow V. Disentangling linear and nonlinear brain responses to evoked deep tissue pain. Pain. 2012; 153(10):2140-2151. [PubMed: 22883925]

43. Loggia ML, Kim J, Gollub RL, Vangel MG, Kirsch I, Kong J, Wasan AD, Napadow V. Default mode network connectivity encodes clinical pain: An arterial spin labeling study. Pain. 2012

44. Loggia ML, Mogil JS, Bushnell MC. Experimentally induced mood changes preferentially affect pain unpleasantness. J Pain. 2008; 9(9):784-791. [PubMed: 18538637]

45. Malinen S, Vartiainen N, Hlushchuk Y, Koskinen M, Ramkumar P, Forss N, Kalso E, Hari R. Aberrant temporal and spatial brain activity during rest in patients with chronic pain. Proc Natl Acad Sci U S A. 2010; 107(14):6493-6497. [PubMed: 20308545]

46. Mazzola L, Faillenot I, Barral FG, Mauguiere F, Peyron R. Spatial segregation of somato-sensory and pain activations in the human operculo-insular cortex. Neuroimage. 2012; 60(1):409-418. [PubMed: 22245639]

47. Medford N, Critchley HD. Conjoint activity of anterior insular and anterior cingulate cortex: awareness and response. Brain structure \& function. 2010; 214(5-6):535-549. [PubMed: 20512367]

48. Morgan VL, Price RR. The effect of sensorimotor activation on functional connectivity mapping with MRI. Magnetic resonance imaging. 2004; 22(8):1069-1075. [PubMed: 15527993]

49. Mouraux A, Diukova A, Lee MC, Wise RG, Iannetti GD. A multisensory investigation of the functional significance of the "pain matrix". Neuroimage. 2011; 54(3):2237-2249. [PubMed: 20932917]

50. Napadow V, Kim J, Clauw DJ, Harris RE. Decreased intrinsic brain connectivity is associated with reduced clinical pain in fibromyalgia. Arthritis Rheum. 2012

51. Napadow V, LaCount L, Park K, As-Sanie S, Clauw DJ, Harris RE. Intrinsic brain connectivity in fibromyalgia is associated with chronic pain intensity. Arthritis Rheum. 2010; 62(8):2545-2555. [PubMed: 20506181]

52. Newton AT, Morgan VL, Gore JC. Task demand modulation of steady-state functional connectivity to primary motor cortex. Hum Brain Mapp. 2007; 28(7):663-672. [PubMed: 17080441]

53. Newton AT, Morgan VL, Gore JC. Task demand modulation of steady-state functional connectivity to primary motor cortex. Hum Brain Mapp. 2007; 28(7):663-672. [PubMed: 17080441]

54. Pavlakovic G, Petzke F. The role of quantitative sensory testing in the evaluation of musculoskeletal pain conditions. Current rheumatology reports. 2010; 12(6):455-461. [PubMed: 20857243]

55. Peltz E, Seifert F, DeCol R, Dorfler A, Schwab S, Maihofner C. Functional connectivity of the human insular cortex during noxious and innocuous thermal stimulation. Neuroimage. 2011; 54(2):1324-1335. [PubMed: 20851770]

56. Pizoli CE, Shah MN, Snyder AZ, Shimony JS, Limbrick DD, Raichle ME, Schlaggar BL, Smyth MD. Resting-state activity in development and maintenance of normal brain function. Proceedings of the National Academy of Sciences of the United States of America. 2011; 108(28):1163811643. [PubMed: 21709227] 
57. Ploner M, Lee MC, Wiech K, Bingel U, Tracey I. Prestimulus functional connectivity determines pain perception in humans. Proc Natl Acad Sci U S A. 2010; 107(1):355-360. [PubMed: 19948949]

58. Polianskis R, Graven-Nielsen T, Arendt-Nielsen L. Modality-specific facilitation and adaptation to painful tonic stimulation in humans. Eur J Pain. 2002; 6(6):475-484. [PubMed: 12413436]

59. Polianskis R, Graven-Nielsen T, Arendt-Nielsen L. Pressure-pain function in desensitized and hypersensitized muscle and skin assessed by cuff algometry. JPain. 2002; 3(1):28-37. [PubMed: 14622851]

60. Price DD, McGrath PA, Rafii A, Buckingham B. The validation of visual analogue scales as ratio scale measures for chronic and experimental pain. Pain. 1983; 17(1):45-56. [PubMed: 6226917]

61. Racine M, Tousignant-Laflamme Y, Kloda LA, Dion D, Dupuis G, Choiniere M. A systematic literature review of 10 years of research on sex/gender and experimental pain perception - part 1: are there really differences between women and men? Pain. 2012; 153(3):602-618. [PubMed: 22192712]

62. Raichle ME, MacLeod AM, Snyder AZ, Powers WJ, Gusnard DA, Shulman GL. A default mode of brain function. Proc Natl Acad Sci U S A. 2001; 98(2):676-682. [PubMed: 11209064]

63. Rainville P, Duncan GH, Price D, Carrier B, Bushnell M. Pain affect encoded in human anterior cingulate but not somatosensory cortex. Science. 1997; 277:968-971. [PubMed: 9252330]

64. Rainville P, Feine JS, Bushnell MC, Duncan GH. A psychophysical comparison of sensory and affective responses to four modalities of experimental pain. Somatosens Mot Res. 1992; 9(4):265277. [PubMed: 1492527]

65. Schneider S, Stone AA, Schwartz JE, Broderick JE. Peak and end effects in patients' daily recall of pain and fatigue: a within-subjects analysis. The journal of pain: official journal of the American Pain Society. 2011; 12(2):228-235. [PubMed: 20817615]

66. Seeley WW, Menon V, Schatzberg AF, Keller J, Glover GH, Kenna H, Reiss AL, Greicius MD. Dissociable intrinsic connectivity networks for salience processing and executive control. J Neurosci. 2007; 27(9):2349-2356. [PubMed: 17329432]

67. Shulman G, Fiez J, Corbetta M, Buckner R, Miezin F, Raichle M, Petersen S. Common blood flow changes across visual tasks: II. Decreases in cerebral cortex. J Cogn Neurosci. 1997; 9:648-663.

68. Smith SM. Fast robust automated brain extraction. Hum Brain Mapp. 2002; 17(3):143-155. [PubMed: 12391568]

69. Spreng RN, Sepulcre J, Turner GR, Stevens WD, Schacter DL. Intrinsic Architecture Underlying the Relations among the Default, Dorsal Attention, and Frontoparietal Control Networks of the Human Brain. Journal of cognitive neuroscience. 2013; 25(1):74-86. [PubMed: 22905821]

70. Spreng RN, Stevens WD, Chamberlain JP, Gilmore AW, Schacter DL. Default network activity, coupled with the frontoparietal control network, supports goal-directed cognition. Neuroimage. 2010; 53(1):303-317. [PubMed: 20600998]

71. Starr CJ, Sawaki L, Wittenberg GF, Burdette JH, Oshiro Y, Quevedo AS, McHaffie JG, Coghill RC. The contribution of the putamen to sensory aspects of pain: insights from structural connectivity and brain lesions. Brain. 2011; 134(Pt 7):1987-2004. [PubMed: 21616963]

72. Tagliazucchi E, Balenzuela P, Fraiman D, Chialvo DR. Brain resting state is disrupted in chronic back pain patients. Neurosci Lett. 2010; 485(1):26-31. [PubMed: 20800649]

73. Terry R, Brodie EE, Niven CA. Exploring the phenomenology of memory for pain: is previously experienced acute pain consciously remembered or simply known? The journal of pain: official journal of the American Pain Society. 2007; 8(6):467-475. [PubMed: 17306627]

74. van den Heuvel MP, Mandl RC, Kahn RS, Hulshoff Pol HE. Functionally linked resting-state networks reflect the underlying structural connectivity architecture of the human brain. Hum Brain Mapp. 2009; 30(10):3127-3141. [PubMed: 19235882]

75. Van Dijk KR, Sabuncu MR, Buckner RL. The influence of head motion on intrinsic functional connectivity MRI. NeuroImage. 2012; 59(1):431-438. [PubMed: 21810475]

76. Verhoeven K, Van Damme S, Eccleston C, Van Ryckeghem DM, Legrain V, Crombez G. Distraction from pain and executive functioning: an experimental investigation of the role of inhibition, task switching and working memory. European journal of pain. 2011; 15(8):866-873. [PubMed: 21397536] 
77. Villemure C, Bushnell MC. Mood influences supraspinal pain processing separately from attention. J Neurosci. 2009; 29(3):705-715. [PubMed: 19158297]

78. Villemure C, Slotnick BM, Bushnell MC. Effects of odors on pain perception: deciphering the roles of emotion and attention. Pain. 2003; 106(1-2):101-108. [PubMed: 14581116]

79. Vincent JL, Kahn I, Snyder AZ, Raichle ME, Buckner RL. Evidence for a frontoparietal control system revealed by intrinsic functional connectivity. Journal of neurophysiology. 2008; 100(6): 3328-3342. [PubMed: 18799601]

80. Whang KC, Burton H, Shulman GL. Selective attention in vibrotactile tasks: detecting the presence and absence of amplitude change. Percept Psychophys. 1991; 50(2):157-165. [PubMed: 1945737]

81. Wiech K, Lin CS, Brodersen KH, Bingel U, Ploner M, Tracey I. Anterior insula integrates information about salience into perceptual decisions about pain. J Neurosci. 2010; 30(48):1632416331. [PubMed: 21123578]

82. Zald DH. The human amygdala and the emotional evaluation of sensory stimuli. Brain Res Brain Res Rev. 2003; 41(1):88-123. [PubMed: 12505650]

83. Zhang D, Raichle ME. Disease and the brain's dark energy. Nature reviews Neurology. 2010; 6(1): $15-28$.

84. Zuo XN, Kelly C, Adelstein JS, Klein DF, Castellanos FX, Milham MP. Reliable intrinsic connectivity networks: Test-retest evaluation using ICA and dual regression approach. Neuroimage. 2009 


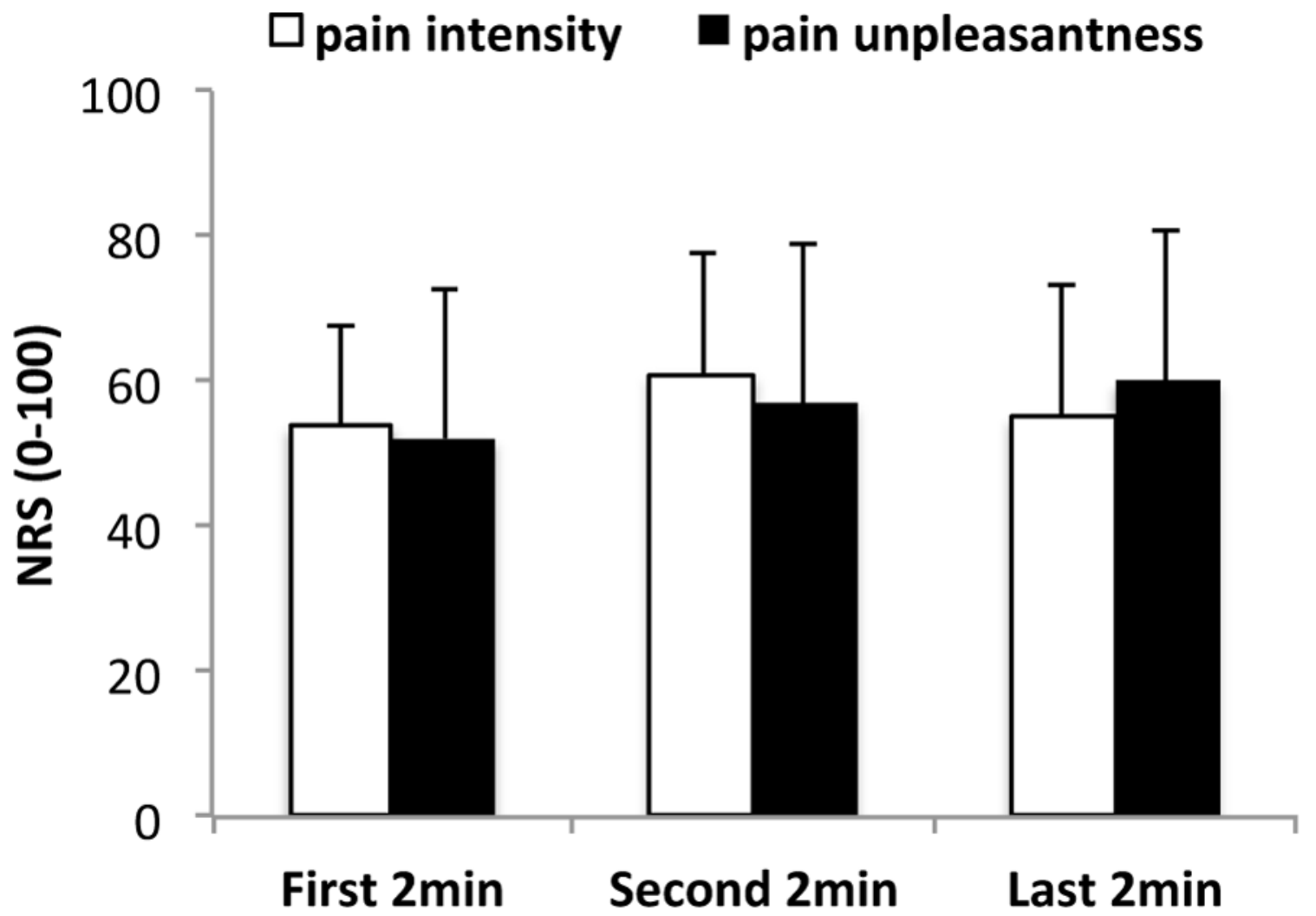

Figure 1. Psychophysical results for pain intensity and unpleasantness

There was no significant change of pain ratings over the stimulation period. Error bars represent standard deviation. 


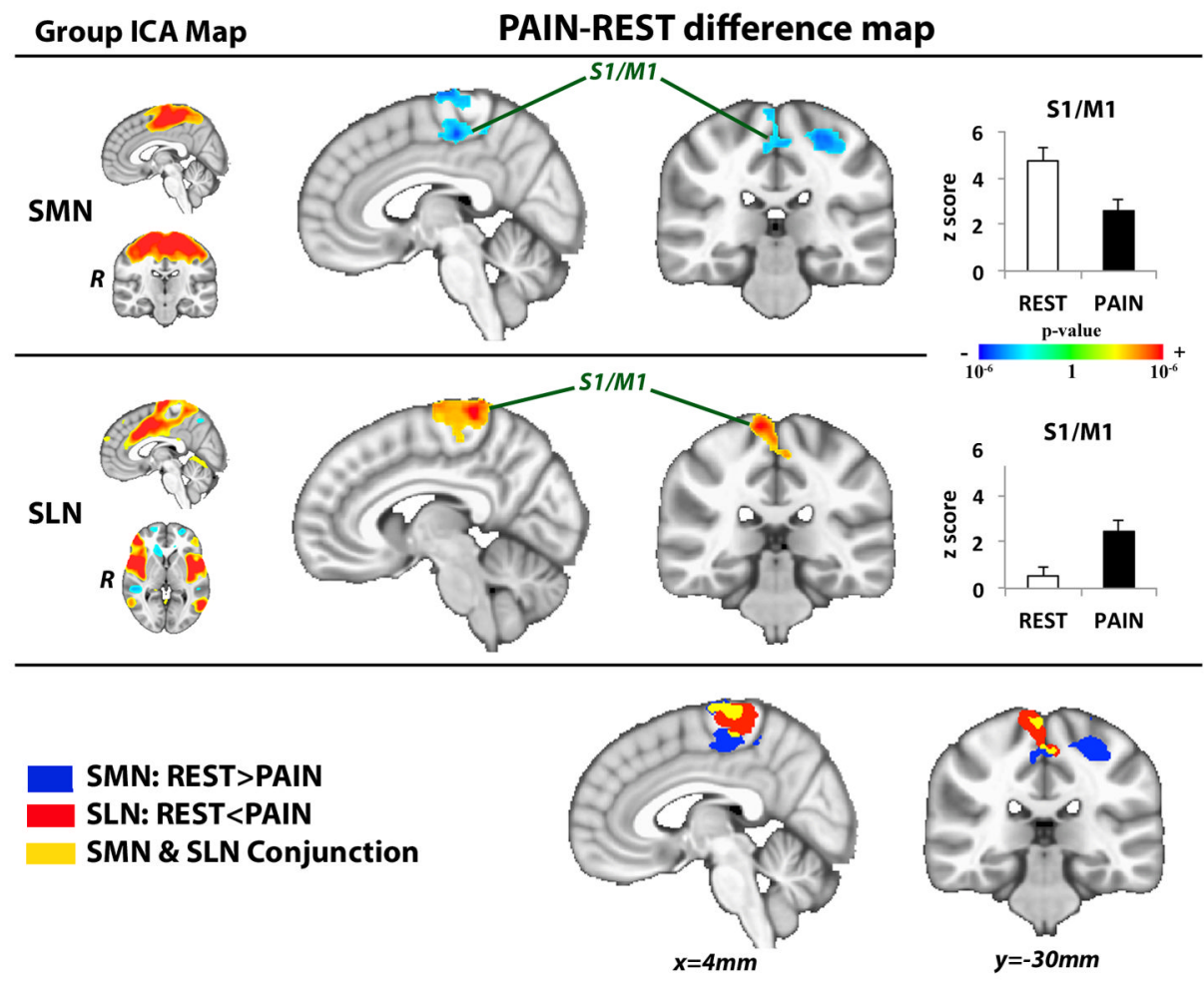

Figure 2. S1/M1 connectivity shifts from SMN to SLN during sustained pain Difference maps contrasting functional connectivity during PAIN versus REST noted increased SLN and reduced SMN connectivity to contralateral S1/M1. ICA=independent component analysis, $\mathrm{SLN}=$ salience network, $\mathrm{SMN}=$ sensorimotor network. Plot error bars denote standard error of the mean. 


\section{Pain induced change in SLN to S1/M1 connectivity vs. change in SMN to S1/M1 connectivity}

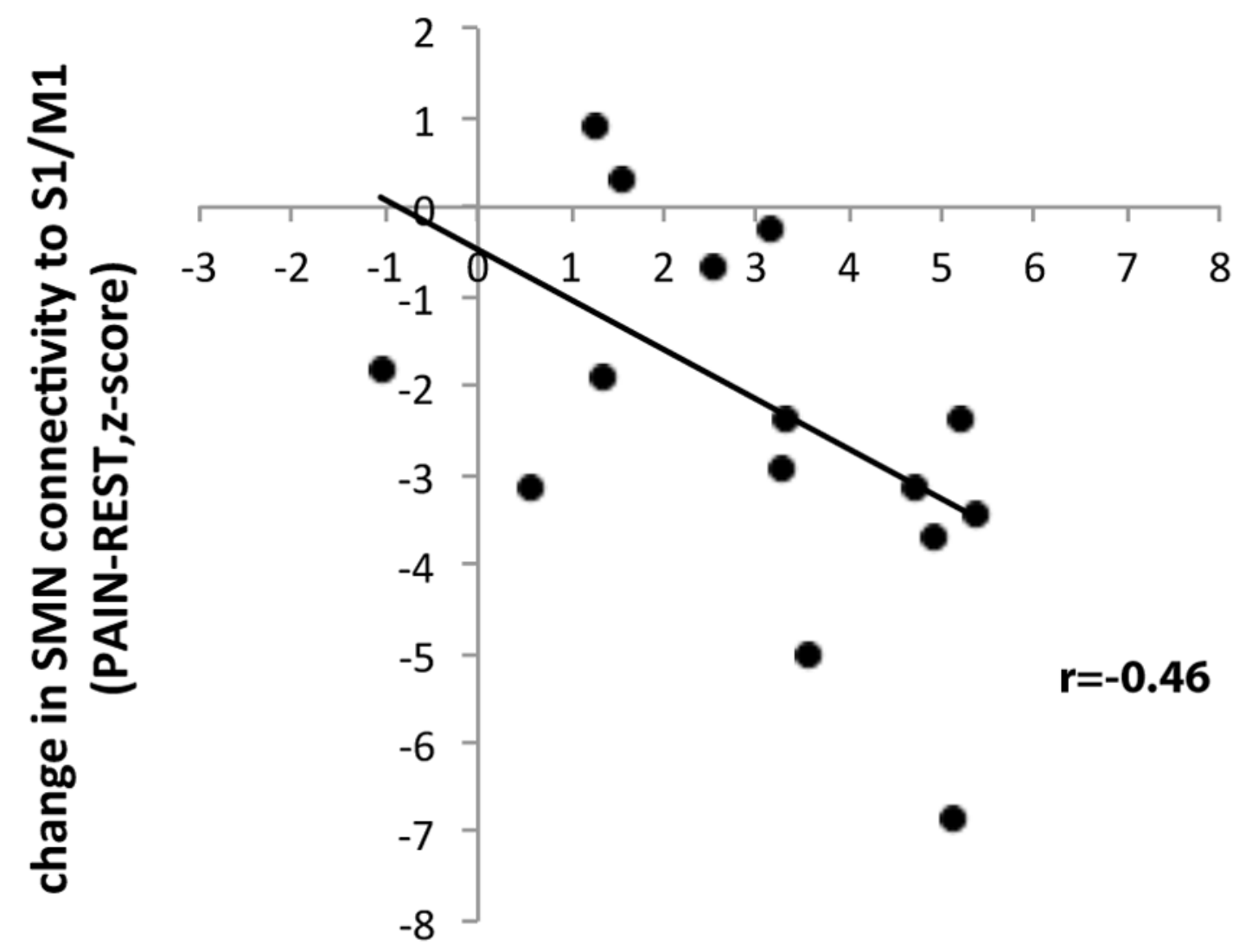

\section{Change in SLN connectivity to S1/M1 (PAIN-REST, z-score)}

Figure 3. Inter-subject correlation between increased SLN connectivity to S1/M1 and decreased SMN connectivity to $S 1 / M 1$

Subjects who responded to sustained pain with greater increased SLN connectivity to S1/M1 (positive z-scores in $\mathrm{x}$ axis represent greater SLN connectivity to S1/M1 during PAIN compared to REST), also demonstrated more decrease in SMN connectivity to S1/M1 (negative z-scores in y axis represent reduced SMN connectivity to S1/M1 during PAIN compared to REST). 


\section{Group ICA Map}

PAIN-REST difference map

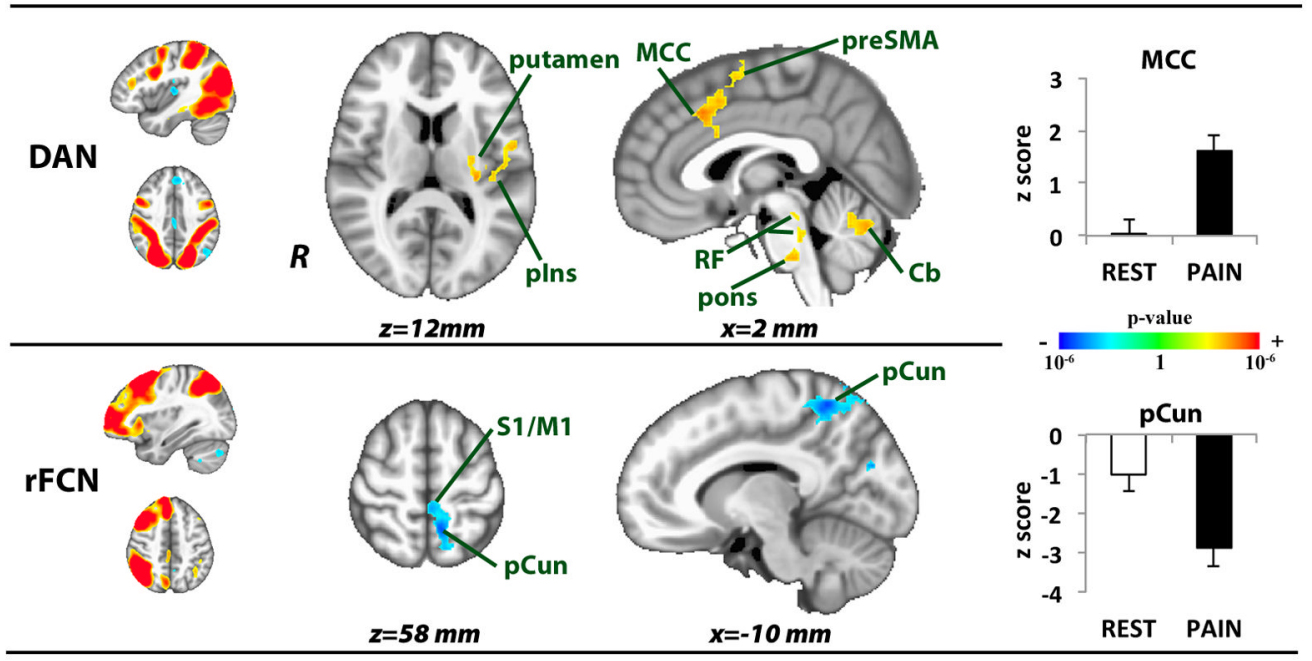

Figure 4. Sustained PAIN alters dorsal attention (DAN) and fronto-parietal control (FCN) network connectivity

During sustained pain, DAN showed greater correlation to preSMA, MCC, left posterior insula, left putamen, midbrain, pontine, reticular formation, and cerebellar nuclei. Greater anti-correlation between right FCN and both $\mathrm{S} 1 / \mathrm{M} 1$ and precuneus was also found during PAIN. preSMA=pre-supplementary motor area, $\mathrm{MCC}=$ mid-cingulate cortex, $\mathrm{pIns}=$ posterior insula, $\mathrm{RF}=$ reticular formation, $\mathrm{Cb}=$ cerebellar nuclei, $\mathrm{pCun}=$ precuneus. 

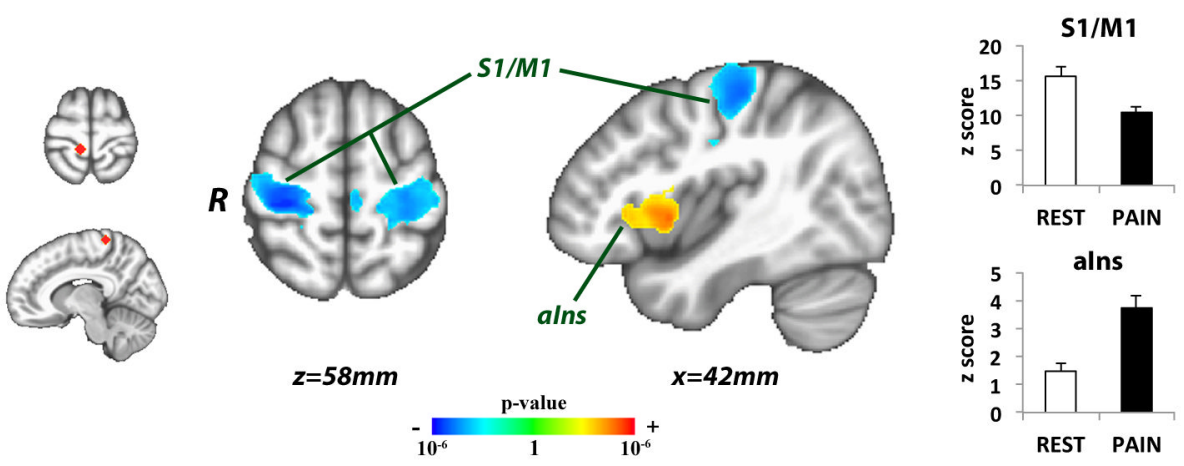

Figure 5. Sustained pain modulates S1/M1 seed connectivity

Using a seed connectivity analysis approach, sustained pain increased connectivity between contralateral leg-region S1/M1 and right anterior insula. Pain also decreased connectivity between contralateral leg-area S1/M1 and bilateral S1/M1 subregions outside of this contralateral leg representation area. (S1/M1=primary somatosensory/motor cortex, aIns=anterior insula) 

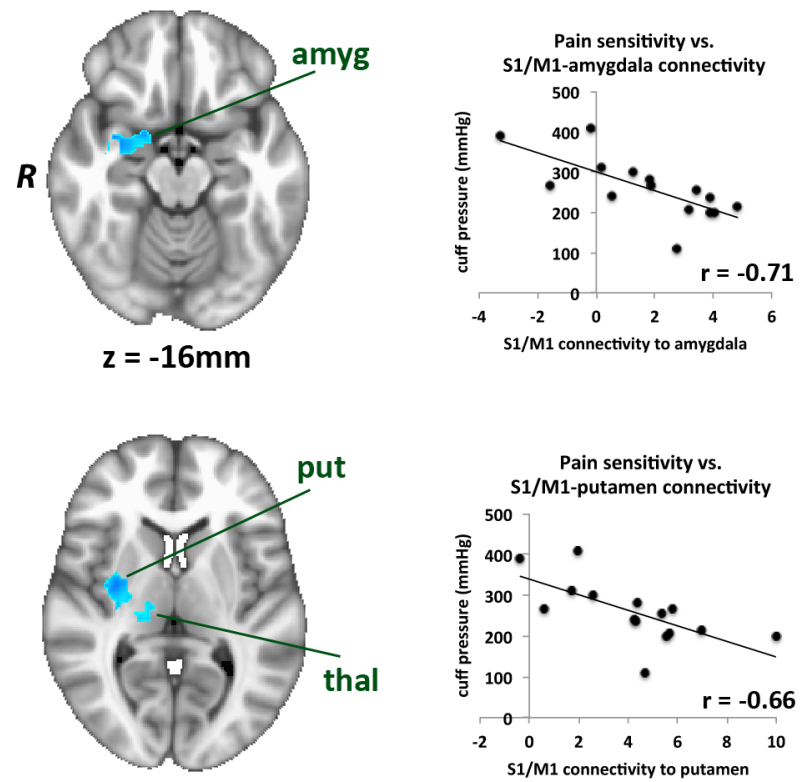

$\mathrm{z}=6 \mathrm{~mm}$
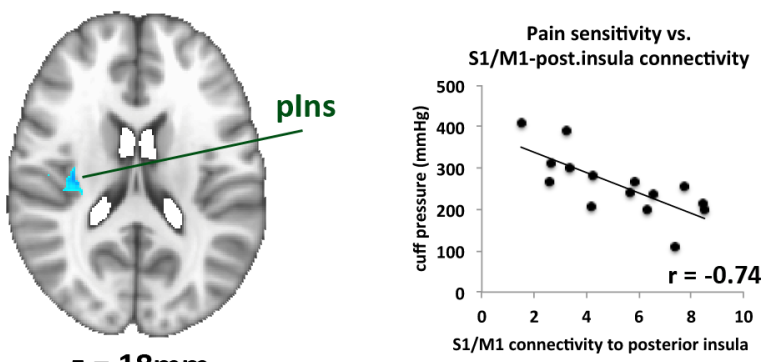

$\mathrm{z}=18 \mathrm{~mm}$

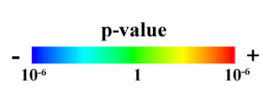

seed: rS1/M1

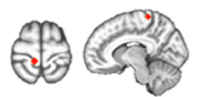

Figure 6. S1/M1 connectivity during sustained pain predicted inter-individual stimulus intensity Stimulus intensity (i.e. cuff pressure evoking 50/100 pain) was negatively correlated to contralateral (somatotopic leg-region) S1/M1 connectivity to the amygdala, putamen, and posterior insula during PAIN. Amyg=amygdala, put=putamen, thal=thalamus, pIns=posterior insula. 


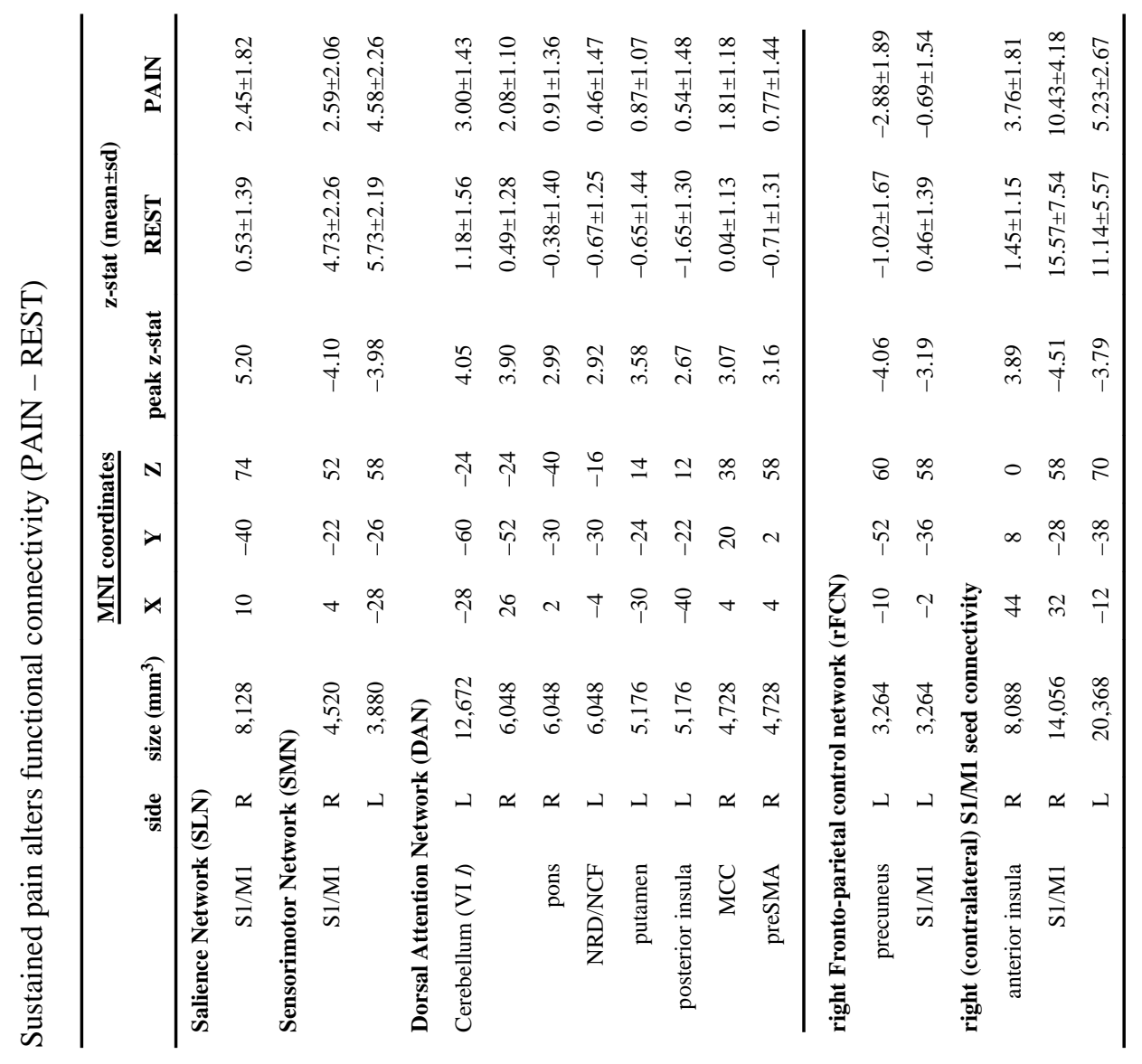




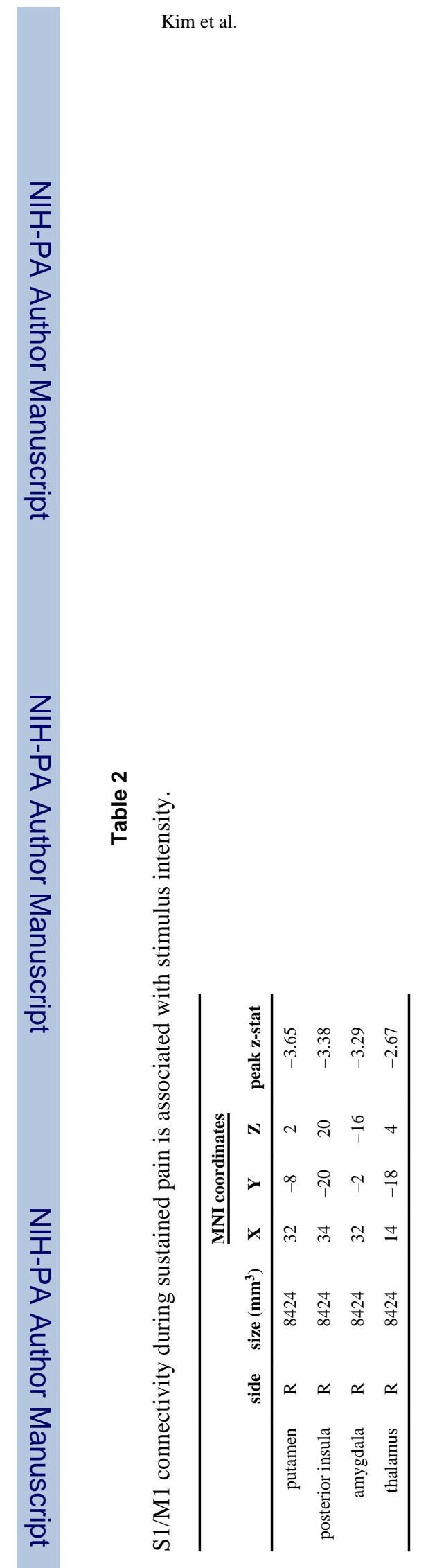

Pain. Author manuscript; available in PMC 2014 August 01. 